\title{
The Impact of Screening Method on HLA Antibody Detection Before and After Lung Transplantation: A Prospective Pilot Study
}

\section{Citation}

Cao, Severine Zheng Yan. 2018. The Impact of Screening Method on HLA Antibody Detection Before and After Lung Transplantation: A Prospective Pilot Study. Doctoral dissertation, Harvard Medical School.

\section{Permanent link}

http://nrs.harvard.edu/urn-3:HUL.InstRepos:41973494

\section{Terms of Use}

This article was downloaded from Harvard University's DASH repository, and is made available under the terms and conditions applicable to Other Posted Material, as set forth at http:// nrs.harvard.edu/urn-3:HUL.InstRepos:dash.current.terms-of-use\#LAA

\section{Share Your Story}

The Harvard community has made this article openly available. Please share how this access benefits you. Submit a story. 
Scholarly Report submitted in partial fulfillment of the MD Degree at Harvard Medical School

Date: 12 February 2018

Student Name: Severine Zheng Yan Cao, BA

Scholarly Report Title: The Impact of Screening Method on HLA Antibody Detection Before and After Lung Transplantation: A Prospective Pilot Study

Mentor Name(s) and Affiliations: Hilary J. Goldberg, MD, MPH, Lung Transplant Program, Division of Pulmonary and Critical Care Medicine, Brigham and Women's Hospital, Boston, Massachusetts, USA

\section{Collaborators, with Affiliations:}

Andrew M. Courtwright, MD, PhD, Division of Pulmonary and Critical Care Medicine, Hospital of the University of Pennsylvania, Philadelphia, Pennsylvania, USA

Anthony M. Lamattina, BS, Lung Transplant Program, Division of Pulmonary and Critical Care Medicine, Brigham and Women's Hospital, Boston, Massachusetts, USA

Indira Guleria, $\mathrm{PhD}$, Clinical Laboratory Division, Tissue Typing Laboratory, Brigham and Women's Hospital, Boston, Massachusetts, USA

Patrick Burkett, MD, PhD, Lung Transplant Program, Division of Pulmonary and Critical Care Medicine, Brigham and Women's Hospital, Boston, Massachusetts, USA

Souheil El-Chemaly, MD, MPH, Lung Transplant Program, Division of Pulmonary and Critical Care Medicine, Brigham and Women's Hospital, Boston, Massachusetts, USA 
The Impact of Screening Method on HLA Antibody Detection Before and After Lung Transplantation: A Prospective Pilot Study

Introduction: Highly sensitive solid phase assays have allowed for increased identification of human leukocyte antigen (HLA) antibodies pre- and post-lung transplant. However, significant center-to-center variability exists in screening techniques. Some institutions perform an initial screen for the presence of any antibodies and then using single-antigen beads (SAB) to determine antibody identity if the pre-screen is positive. Other institutions do not pre-screen, using SAB only. As a result, there are conflicting data on the epidemiology and relevance of pre- and posttransplant anti-HLA antibodies.

Methods: We performed a single center pilot prospective study of adult patients undergoing lung transplantation between July 2015 and October 2016. Enrolled patients had HLA antibody testing prior to transplant and within 3 months post-transplant by 1) pre-screening followed by SAB testing and 2) by SAB alone.

Results: Among the 29 enrolled patients, pre-transplant HLA antibodies were found at MFI 1000-3000 in 7 (24.1\%) and at MFI >3000 in 2 (6.9\%) with the use of pre-screening, and MFI 1000-3000 in 11 (39.3\%) patients and at MFI >3000 in 5 patients (17.9\%) with SAB alone. The additional pre-transplant antibodies identified by SAB only were not associated with positive retrospective B-cell crossmatch results. Pre-transplant HLA antibody status was more strongly associated with donor-specific HLA antibody development when assessed by pre-screening (OR 9.5, CI 0.8 to $109.2 ; \mathrm{p} 1 / 40.07$ ) versus by SAB alone (OR 1.2, 95\% CI 0.2 to 5.5; p 1/4 0.88).

Conclusion: The use of SAB alone is associated with increased identification of HLA antibodies compared to pre-screening followed by SAB. The additional antibodies detected and not associated with positive retrospective B-cell crossmatch or donor-specific HLA antibody formation. This suggests that the additional sensitivity from SAB testing may have limited clinical significance, and its use alone may therefore reduce opportunities for transplant and increase waitlist time. 


\section{Student's Role}

Design: The framework of the project was designed by Drs. Hilary Goldberg and Souheil ElChemaly. On joining the project in the summer of 2015, I worked with Dr. Goldberg to create our project database. I also designed a system to identify eligible patients and log the patient recruitment process. I collaborated with Dr. El-Chemaly, his lab members Dr. Ye Cui and Anthony Lamattina, and the Tissue Typing Lab to plan out the steps for recruiting patients, obtaining consent, and collecting and storing patient samples.

Execution: With guidance from Dr. Goldberg, I initiated the process of recruiting patients and collecting samples. Every week eligible patients were identified and asked in-person for informed consent. I then coordinated with Dr. El-Chemaly's lab members for sample drop-off and storage. At the start of the summer of 2017, this task was handed to Dr. Andrew Courtwright, to allow me to focus on my third-year clerkships. Approximately every six months as patient sera were collected, I coordinated with the Tissue Typing Lab to arrange HLA antibody screening for sera collected to date. Reports were then interpreted and logged into our database. I also performed chart biopsies to log recipient and donor demographic information as well as clinical outcomes of interest.

Analysis: Dr. Courtwright met with me at the early stages of our project to teach me the basics of logistic regression and relevant statistical tests. The analyses we performed together contributed to a poster of an early version of our manuscript presented at the 2017 annual meeting of the International Society for Heart and Lung Transplantation. All subsequent analyses in the final version of our manuscript were performed by Dr. Courtwright.

Writing: The writing of the manuscript was split between myself and Dr. Courwright, with me writing the introduction and Dr. Courwright the methods, results, and discussion. The final draft was edited by all authors. Dr. Courwright was responsible for addressing reviewer concerns and manuscript revisions during the peer review process. 


\section{Link to manuscript:}

https://www.ncbi.nlm.nih.gov/pubmed/?term=The+impact + of + screening + method + on + HLA + ant ibody + detection + before + and + after + lung + transplantation $\% 3 \mathrm{~A}+\mathrm{A}+$ prospective + pilot + study

\section{Citation of manuscript:}

Cao S, Courtwright AM, Lamattina AM, Guleria I, Burkett P, El-Chemaly S, Goldberg HJ. The impact of screening method on HLA antibody detection before and after lung transplantation: A prospective pilot study. J Heart Lung Transplant. 2017 Nov 22. pii: S1053-2498(17)32119-8. doi: 10.1016/j.healun.2017.11.018. [Epub ahead of print] PubMed PMID: 29229269. 


\section{RESEARCH CORRESPONDENCE}

\section{The impact of screening method on HLA antibody detection before and after lung transplantation: A prospective pilot study}

Severine Cao, BA, a,b,1

Andrew M. Courtwright, MD, PhD, ${ }^{c, 1}$

Anthony M. Lamattina, BS, ${ }^{a, b}$

Indira Guleria, $\mathrm{PhD}$, ${ }^{\mathrm{a}, \mathrm{d}}$

Patrick Burkett, MD, PhD, a,b

Souheil El-Chemaly, MD, MPH, a,b and

Hilary J. Goldberg, MD, MPH ${ }^{a, b}$

From the ${ }^{a}$ Harvard Medical School, Boston,

Massachusetts, USA; ${ }^{b}$ Lung Transplant

Program, Division of Pulmonary and Critical

Care Medicine, Brigham and Women's

Hospital Boston, Massachusetts, USA;

${ }^{c}$ Division of Pulmonary and Critical Care

Medicine, Hospital of the University of

Pennsylvania, Philadelphia, Pennsylvania,

USA; and the ${ }^{d}$ Clinical Laboratory Division,

Tissue Typing Laboratory, Brigham and

Women's Hospital, Boston, Massachusetts,

USA.

Despite the development of solid-phase Luminex-based assays using human leukocyte antigen (HLA)-coated microbeads, there is significant center variability in the identification of HLA antibodies in lung transplantation. Some institutions screen for the presence of any antibodies and then use single-antigen beads ( $\mathrm{SAB}$ ) to determine antibody identity if the pre-screen is positive (the pre-screen method). ${ }^{1}$ Other centers do not pre-screen, using SAB only. ${ }^{2}$ $\mathrm{SAB}$, however, are significantly more sensitive than prescreening. Because screening beads are coated with less of a specific antigen, SAB can identify antibodies of lower avidity. In addition, false positive antibodies to denatured epitopes present on SAB can occur. ${ }^{3}$ Concern about the relevance of all antibodies detected through $\mathrm{SAB}$ has led to the recommendation that kidney transplant candidates not be denied potential donors because of antibodies identified by $\mathrm{SAB}$ alone. ${ }^{4}$ In the published lung transplantation literature, however, at least half of the centers make HLA-antibody decisions based on SAB alone. The objective of this study

\footnotetext{
${ }^{1}$ These authors have contributed equally to this study.

Reprint requests: Hilary J. Goldberg, MD, MPH, Peter Bent Brigham Building, Brigham and Women's Hospital, 75 Francis Street, Boston, MA 02114. Telephone: +617-732-7420. Fax: +617-582-6102.

E-mail address: hjgoldberg@partners.org
}

was to evaluate the detection of pre- and post-transplant HLA antibodies using pre-screen followed by SAB as compared with $\mathrm{SAB}$ alone.

The current investigation was a single-center, prospective cohort study of adults undergoing lung transplantation between July 1, 2015 and October 1, 2016. Donors were considered acceptable if both Class I and II donor-specific antibodies (DSA) were absent at a mean fluorescence index (MFI) $>3,000$ or, if DSA were present, a prospective cytotoxic crossmatch was negative. In the latter setting, management included plasmapheresis within 24 hours of transplantation and continued until assessment of allograft function.

Patients were screened prospectively for research purposes for HLA antibodies pre-transplant and within 3 months \pm 7 days post-transplant. Pre- and post-transplant samples were evaluated using 2 approaches. First, in the prescreening method, samples were pre-screened for antibody positivity using LABscreen Mixed Product (One Lambda, Canoga Park, CA) followed by SAB if pre-screen positive (Figure 1). Second, in the SAB-only approach, samples were analyzed directly with the LABscreen single-antigen assay without pre-screen. HLA antibodies detected at MFI $>1,000$ post-transplant and not present pre-transplant were considered de novo (dn). Screening results were not available to subjects' physicians unless a separate test was sent for clinical purposes.

We categorized patients in 3 groups: no HLA antibodies pre-transplant; antibodies at MFI 1,000 to 3,000; and antibodies at MFI $>3,000$. For each screening method (pre-screen followed by SAB or SAB only), we compared those 3 groups according to sociodemographics, positive retrospective B-cell crossmatch and identification of HLA antibodies post-transplant.

Twenty-nine patients were enrolled. Only 1 patient received intravenous immunoglobulin and plasmapharesis at the time of transplant. Antibodies were assessed at a median of 1.3 months post-transplant (interquartile range [IQR] 1.0 to 2.2). Seven of the 9 HLA-antibody screens performed for a clinical indication were negative for DSA. Neither of the patients with positive DSA received treatment.

The pre-screening method detected pre-transplant HLA antibodies at MFI 1,000 to 3,000 in 7 patients (24.1\%) and at MFI >3,000 in 2 patients (6.9\%) (Table 1). The use of $\mathrm{SAB}$ alone detected pre-transplant HLA antibodies at MFI 1,000 to 3,000 in $11(39.3 \%)$ and at MFI $>3,000$ in 5 (17.9\%). Patients were more likely to have antibodies detected pre-transplant using $\mathrm{SAB}$ alone than with prescreening $(57.2 \%$ vs $31.0 \% ; p=0.05)$. Non-white patients 


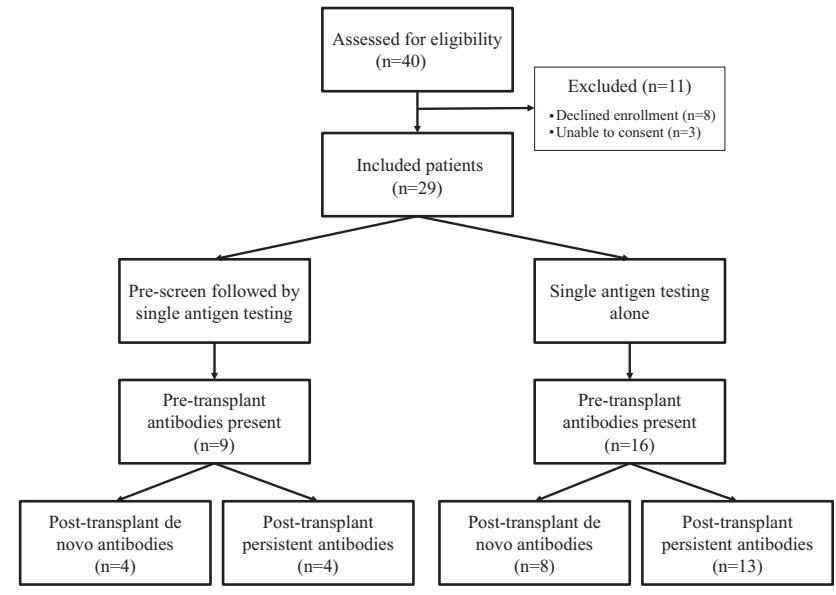

Figure 1 Study cohort and testing. The same pre- and posttransplant samples were tested using 2 approaches. In the pre-screen method, samples with a positive pre-screen, defined as a normalized background ratio of $>2.5$ for Class I antibodies and $>2.0$ for Class II antibodies, were then analyzed with the LABscreen single-antigen assay (One Lambda, Canoga Park, CA). The assay was considered positive for Class I antibodies if any bead for a given antigen was detected at MFI $>1,000$, and was considered positive for Class II antibodies if $\geq 60 \%$ of the beads for a given antigen were detected at MFI $>1,000$. In the SAB-only approach, pre-screening was not performed and samples were directly analyzed with the LABscreen single-antigen assay with the same cut-offs for positivity. For clinical purposes, our institution utilizes pre-screen followed by SAB. All transplant recipients received basiliximab and methylprednisolone induction, and all were maintained on tacrolimus, mycophenolate mofetil and prednisone. were more likely to have HLA antibodies detected with SAB alone.

The additional pre-transplant antibodies identified by SAB only were not associated with positive retrospective B-cell crossmatch results. The use of pre-screening detected posttransplant HLA antibodies in 8 patients $(27.6 \%), 3$ at MFI $>3,000$, whereas the use of SAB alone detected posttransplant HLA antibodies in 16 patients (57.1\%), 5 at MFI $>3,000(p=0.03)$. Pre-transplant antibodies were not more likely to persist post-transplant when identified by pre-screen (4 of $8,50.0 \%$ ) vs SAB alone (13 of $16,81.2 \% ; p=0.16$ ).

dnHLA antibodies were detected post-transplant in 4 $(13.8 \%)$ vs $8(28.6 \%)$ patients using the pre-screening method compared with SAB alone. Seventy percent of the additional individual antibodies identified by SAB were Class I and none were MFI >3,000 or DSA. Pre-transplant HLA antibody status assessed by the pre-screening method was more strongly associated with dnHLA antibody development (odds ratio [OR] 9.5, 95\% confidence interval [CI] 0.8 to $109.2 ; p=0.07)$ than antibody status assessed by $\mathrm{SAB}$ alone (OR 1.2, 95\% CI 0.2 to $5.5 ; p=0.88$ ).

Solid-phase antibody assays allow increased identification of HLA antibodies, but consensus around the appropriate approach to antibody detection has lagged in lung transplantation. In our study, when SAB were used without pre-screen, significantly more patients had antibodies at MFI $>1,000$ pre- and post-transplant. The increased sensitivity of SAB, particularly for low-level antibody, has also been described for kidney transplantation. ${ }^{3-5}$ Similarly, we found

Table 1 Comparison of Pre-screening After SAB vs SAB Only on Identification of Pre- and Post-transplant HLA Antibodies, Grouped by MFI $(n=29)$

\begin{tabular}{|c|c|c|c|c|c|c|c|c|c|}
\hline & \multirow[b]{2}{*}{$\begin{array}{l}\text { All subjects } \\
(n=29)\end{array}$} & \multicolumn{3}{|c|}{$\begin{array}{l}\text { Pre-transplant HLA antibodies } \\
\text { detected by pre-screen followed } \\
\text { by SAB }\end{array}$} & \multirow[b]{2}{*}{$p$} & \multicolumn{3}{|c|}{$\begin{array}{l}\text { Pre-transplant HLA antibodies detected } \\
\text { by SAB only }\end{array}$} & \multirow[b]{2}{*}{$p$} \\
\hline & & $\begin{array}{l}\text { None } \\
(n=20)\end{array}$ & $\begin{array}{l}\text { MFI } 1,000 \text { to } \\
3,000(n=7)\end{array}$ & $\begin{array}{l}\text { MFI } \\
\geq 3,000 \\
(n=2)\end{array}$ & & $\begin{array}{l}\text { None } \\
(n=12)\end{array}$ & $\begin{array}{l}\text { MFI } 1,000 \text { to } \\
3,000(n=11)\end{array}$ & $\begin{array}{l}\text { MFI } \geq 3,000 \\
(n=5)^{\mathrm{a}}\end{array}$ & \\
\hline All subjects & & $20(69.0)$ & $7(24.1)$ & $2(6.9)$ & & $12(42.8)$ & $11(39.3)$ & $5(17.9)$ & \\
\hline Age $>60$ years & $13(44.8)$ & $10(50.0)$ & $2(28.6)$ & $1(50.0)$ & 0.70 & $5(41.7)$ & $4(36.4)$ & $4(80.0)$ & 0.32 \\
\hline Male gender & $15(51.7)$ & $12(60.0)$ & $2(28.6)$ & $1(50.0)$ & 0.35 & $8(66.6)$ & $5(45.4)$ & $2(40.0)$ & 1.0 \\
\hline Non-white race & $3(10.3)$ & $1(5.0)$ & $1(14.3)$ & $1(50.0)$ & 0.10 & $0(0.0)$ & $1(9.1)$ & $2(40.0)$ & 0.04 \\
\hline Pulmonary fibrosis & $16(55.1)$ & $11(55.0)$ & $4(57.1)$ & $1(50.0)$ & 1.00 & $6(50.0)$ & $6(54.5)$ & $4(80.0)$ & 0.54 \\
\hline $\begin{array}{l}\text { Positive retrospective } \\
\text { B-cell crossmatch }\end{array}$ & $5(17.2)$ & $3(15.0)$ & $2(28.6)$ & $0(0.0)$ & 0.71 & $2(16.7)$ & $2(18.2)$ & $1(20.0)$ & 1.00 \\
\hline $\begin{array}{l}\text { Post-transplant HLA } \\
\text { antibodies MFI } \\
>1,000^{\mathrm{b}}\end{array}$ & $8(27.6)$ & $2(10.0)$ & $4(57.1)$ & $2(100.0)$ & 0.78 & $3(25.0)$ & $8(72.7)$ & $5(100.0)$ & 0.007 \\
\hline $\begin{array}{l}\text { Post-transplant HLA } \\
\text { antibodies MFI } \\
>3,000\end{array}$ & $3(10.3)$ & $0(0.0)$ & $2(28.6)$ & $1(50.0)$ & $<0.001$ & $0(0.0)$ & $3(27.3)$ & $2(40.0)$ & 0.07 \\
\hline \multicolumn{10}{|c|}{$\begin{array}{l}\text { Data are expressed as number }(\%) \text {. HLA, human leukocyte antigen; MFI, mean fluorescence intensity; SAB, single-antigen bead. } \\
{ }^{a} \text { The HLA specificities of MFI }>3,000 \text { antibodies detected pre-transplant in SAB but not pre-screen were B8, DQ7 and DR18. }\end{array}$} \\
\hline $\begin{array}{l}{ }^{\mathrm{b}} \text { Includes both persist } \\
\text { A66, A68, B51, B57, B58 }\end{array}$ & $\begin{array}{l}\text { Id de-novo } \mathrm{H} \\
\text { and } 3 \text { were } \mathrm{C}\end{array}$ & $\begin{array}{l}\text { LA antibodies } \\
\text { lass II (DR8, }\end{array}$ & $\begin{array}{l}\text { es. Of the } 10 \text { de-no } \\
\text { DR10, DR18). The }\end{array}$ & o HLA antib & $\begin{array}{l}\text { odies ident } \\
\text { ties of the }\end{array}$ & tified by $S A B$ & $\begin{array}{l}\text { 3. but not pre-scree } \\
\text { vith MFI }>3,000 \text { ide }\end{array}$ & ר, 7 were Cla & I (A11, \\
\hline
\end{tabular}


that use of the MFI $>3,000$ threshold reduced the pretransplant prevalence of sensitized patients from $31.0 \%$ to $6.9 \%$ and from $57.1 \%$ to $17.9 \%$ with pre-screened samples and SAB-only samples, respectively. In our tissue typing laboratory's experience, $7 \%$ of $\mathrm{SAB}$ react randomly to normal male serum at MFI $>1,000$ compared with $0.5 \%$ at MFI 3,000, suggesting increased false positives with $\mathrm{SAB}$ alone. Therefore, centers using a combination of SAB only with an MFI $>1,000$ cut-off to assess pre-transplant HLA antibodies may be more likely to identify candidates as sensitized, reducing opportunities for transplant and increasing waitlist time. We also found that the additional pretransplant antibodies identified through SAB alone were not associated with positive retrospective B-cell crossmatch and that the use of SAB alone decreased the association between pre-transplant sensitization and dnHLA antibody formation. This suggests that the additional sensitivity from SAB testing alone may have limited clinical significance.

This study has several limitations. First, our sample was only powered to detect large effect sizes. Second, the pretransplant prevalence and post-transplant incidence of HLA antibodies reflects the specific characteristics of our population. Third, because our focus was on early HLA antibodies, we do not have data on the impact of antibodies on antibody-mediated rejection or chronic lung allograft dysfunction, according to method of detection.

In this prospective study, the use of SAB without prescreening was associated with increased identification of
HLA antibodies of unclear clinical significance. Additional data should be collected on dnDSA and allograft outcomes as related to pre-transplant HLA antibody status and method of detection.

\section{Disclosure statement}

The authors have no conflicts of interest to disclose. This study was supported by the National Institutes of Health (5T32-HL-00763330 and R01-HL130275). The sponsors had no role in the design of the study, collection and analysis of the data, or preparation of the manuscript.

\section{References}

1. Morrell MR, Pilewski JM, Gries CJ, et al. De novo donor-specific HLA antibodies are associated with early and high-grade bronchiolitis obliterans syndrome and death after lung transplantation. J Heart Lung Transplant 2014;33:1288-94.

2. Bosanquet JP, Witt CA, Bemiss BC, et al. The impact of pre-transplant allosensitization on outcomes after lung transplantation. J Heart Lung Transplant 2015;34:1415-22.

3. Morales-Buenrostro LE, Terasaki PI, Marino-Vázquez LA, et al. "Natural" human leukocyte antigen antibodies found in nonalloimmunized healthy males. Transplant 2008;86:1111-5.

4. Gombos P, Opelz G, Scherer S, et al. Influence of test technique on sensitization status of patients on the kidney transplant waiting list. Am J Transplant 2013;13:2075-82.

5. Gebel HM, Bray RA. HLA antibody detection with solid phase assays: great expectations or expectations too great? Am J Transplant 2014;14: 1964-75. 